\title{
Textile wastewater treatment via membrane distillation
}

\author{
Appanu Sushvanth Reddy, Sarita Kalla** Z.V.P. Murthy ${ }^{*}$ \\ Department of Chemical Engineering, Sardar Vallabhbhai National Institute of Technology, Surat 395007, Gujarat, India \\ "These authors contributed equally to this work.
}

\begin{abstract}
Due to the skyrocketed population growth and to meet clean water requirements, it is mandatory to develop techniques for proper conversion of wastewater and seawater into clean water. Textile industries generate a massive amount of wastewater. Processing of wastewater obtained from textile wastewater is more significant because of the pollutants present in the wastewater. Conventional separation processes like physical treatment, chemical treatment, and biological treatment are not pertinent in the current situation because of their lower separation efficiencies. Non-conventional separation processes are playing critical roles in ensuring the highest separation possible till date. Of these, membrane distillation (MD), which works based on trans-membrane vapor pressure difference, gives nearly $100 \%$ rejection. Thus, the present review highlights the latest work related to the separation of wastewater from the textile industries. This review also studies the limitations in terms of membrane fouling in the field of MD. Lastly, future work regarding membrane modification, MD integration, and MD commercialization are discussed. It is believed that these integrated membrane-driven separation processes will be rendered into relevant innovations in this field.
\end{abstract}

Keywords: MD integration, Membrane distillation, Membrane fouling, Textile industries, Wastewater treatment

\section{Introduction}

Water is the essential living source for human life and plays a vital role in the sustainable development of a country by fulfilling the needs of people. With the increase in population growth and rapid industrialization, the demand for freshwater resources is continuously increasing [1]. Since freshwater availability is significantly less, the need for reusability of wastewater came into existence [2]. One of the major sources of wastewater globally is the textile industry. Complexity in separation arises because of the wide range of pollutants obtained from various processing techniques employed in textile industries, making the separation difficult [3]. The different textile industries during the manufacturing of various fabric items require the use of several processing techniques like scouring, dyeing, sizing, de-sizing, bleaching, printing, and finishing, resulting in the generation of wastewater [4]. The dyeing process utilizes high amounts of organic dyes, additives, and salts to produce better-quality textiles that eventually lead to acute water pollution. Therefore, proper treatment of wastewater is necessary before reusing it. In addition to textile wastewater, surface water is widely contaminated because of the enormous usage of pesticides which are harmful to both biotic and abiotic environments [5, 6].

Until now, many survey papers have been written by different researchers around the world on the different types of wastewater treatment using $\mathrm{MD}$, although very few survey papers specifically focused on the textile wastewater treatment using $\mathrm{MD}$.

Tibi et al. [7] focussed more on membrane fabrication and surface modification for different types of wastewater treatment to enhance membrane hydrophobicity and rejection efficiency. These membrane fabrication methods include improved phase inversion technique (using alcohol as non-solvent in the place of deionized water), incorporating perfluorinated polymers, and hydrophobic polymer blending. Surface modification methods include the addition of inorganic additives (incorporation of nanomaterials), electrospinning, and chemical modification (to reduce surface energy thereby increasing hydrophobicity). Nasir et al. [8] studied the preparation of polymeric nanocomposite membranes and their applications in wastewater treatment. These membranes are eco-friendly and are energy efficient. On a lab scale, these membranes possessed improved mechanical strength and antibacterial properties which reduced biofouling and enhanced membrane stability. Pavithra et al. [9] reviewed industrial wastewater treatment using various treatment techniques like removing colorants present
This is an Open Access article distributed under the terms of the Creative Commons Attribution Non-Commercial License (http://creativecommons.org/licenses/by-nc/3.0/) which permits unrestricted non-commercial use, distribution, and reproduction in any medium, provided the original work is properly cited.

Copyright (C) 2022 Korean Society of Environmental Engineers
Received May 08, 2021 Accepted September 22, 2021

${ }^{\dagger}$ Corresponding author

E-mail: sarita87mishra@gmail.com

Tel: +261-2201642

ORCID: 0000-0003-0126-2945 
in the wastewater. These treatment techniques include advanced oxidation processes, membrane processes like nanofiltration, reverse osmosis, membrane distillation, etc. These processes exhibited more than $80-90 \%$ efficiency for the removal of dyes like azo dye, methylene blue, etc. Neoh et al. [10] and Jegatheesan et al. [11] focussed majorly on wastewater treatment using membrane bioreactor integrated with other separation processes. The results promised to show high performance in organic removal which makes this process an alternative for the reusability of water. Shirazi and Kargari [12] investigated various types of membrane distillation and its applications. The authors emphasized more on important features like $100 \%$ rejection and stable performance even at higher concentrations of feed. Also, low permeate flux and pore wetting should be taken care of. Apart from the experimental work, Madalosso et al. [13] investigated dye wastewater using DCMD experimentally and validated with MATLAB modelling. The results showed that permeate flux obtained from mathematical model are in good agreement with experimental results with error less than $10 \%$.

With the increase in operating time, foulants get deposited on the membrane surface and significantly impacts permeate flux and rejection. To control fouling, properties of membrane like hydrophobicity should be considered. Hydrophobicity is one of the important parameters in $\mathrm{MD}$, which helps in reducing fouling by increasing the contact angle of the membrane. To increase hydrophobicity, membrane modification techniques like the addition of nanomaterials and surface modification methods are widely used. Nanomaterials like $\mathrm{SiO}_{2}$ [14], $\mathrm{TiO}_{2}$ [15], graphene [16], zeolites etc., are mainly used for wastewater treatment. $\mathrm{TiO}_{2}$ showed great promise in separating dye wastewater from these nanomaterials due to its photocatalytic activity [17]. So, $\mathrm{TiO}_{2}$ stands one step ahead in water purification techniques. Incorporation of $\mathrm{TiO}_{2}$ with ZSM-5 on $\mathrm{MoS}_{2}$ nanosheets [18] showed $100 \%$ rejection of arsenite present in wastewater [19]. Balati et al. [20] synthesized different crystal morphologies of black $\mathrm{TiO}_{2}$ nanoparticles using pulsed laser ablation in the liquid method. The synthesized modified $\mathrm{TiO}_{2}$ exhibited 99\% rejection for methylene blue after $60 \mathrm{~min}$ of operation. The authors' work followed the pathway of developing eco-friendly modified nanomaterials with photocatalytic activity for water purification and reclamation.

The membrane-based separation processes provide a better platform for effluent treatment in textile industries because of their lower operating cost [21]. The lower level of aerobic biodegradation and the presence of dissolved salts in the effluent stream makes it unsuitable for separation by conventional treatment processes like flocculation, coagulation, and adsorption [22]. After treating effluent using membrane technology, the permeate was used to dyeing polyester fabric within the same unit [23]. Membrane distillation (MD) is one of the promising non-conventional separation processes in the present world. Membrane distillation operates based on the trans-membrane vapor pressure difference across the membrane [24-26]. Apart from wastewater separation, MD is used for desalination, azeotropic mixture separation, processing of food, etc. $[27,28]$. Thus, the current survey paper focused on the MD treatment for textile wastewater treatment, membrane modification techniques and concentrate on some of the hybrid $\mathrm{MD}$ process used for the same purpose. Table S1 summarizes the survey papers that considered wastewater treatment using $\mathrm{MD}$ as the central theme. Some of them also considered the textile wastewater treatment as the sub-section. Finally, the main contributions of the current review paper are encapsulating in Fig. S1.

\section{Types of Textile Effluent and Their Characterization}

The textile industry is one of the major export and import industries in the world. Countries like China and the European Union (EU) have a major share in textile exports [29]. Regarding textile imports, EU and USA have a significant share among other countries [30]. As far as India is concerned, major textile industries are located in Ahmedabad, Bombay, Chennai, and Coimbatore. Medium and small-scale textile industries are situated all over the country [31]. The textile industries are classified into cellulosic fibers, protein fibers, and synthetic fibers based on the fiber used. Cellulose fibers are acquired from a plant source like cotton, rayon, hemp, and lyocell [32]. Protein fibers are taken from animals and comprise wool, silk, angora, and cashmere; and synthetic fibers are composed of polyester, polypropylene, nylon, spandex, and acetate [33].

Textile wastewater is loaded with high amounts of dyes, chemical oxygen demand (COD), biochemical oxygen demand (BOD), total dissolved solids (TDS), and heavy metals. Out of them, dyes are considered the main constituents of textile wastewater because of their high concentration in wastewater [34].

The chemical structure of dyes is also an essential parameter of classification, and based on this; dyes are classified as anionic, cationic, and non-ionic dyes. Direct, reactive, and acid dyes come under anionic dyes. Major non-ionic dyes would not get ionized in the environment. Some non-ionic dyes are polyesters. Cationic dyes include azo-basic and reactive dyes [35]. Based on COD, dyes are classified [36] as: (i) If COD is greater than 1,500 ppm, then the dye comes under a high concentration level; (ii) If COD is in between $800-1,500 \mathrm{ppm}$, then the dye comes under average concentration level; and (iii) If COD is less than $800 \mathrm{ppm}$, then the dye comes under lower concentration level.

Based on the fabrics, different types of dyes are used in the textile industry. For dyeing cellulose fibers, reactive dyes, direct dyes, naphthol dyes, and indigo dyes are generally used. Similarly, for dyeing protein fibers, acid, and lanaset dyes, while for dyeing synthetic fibers basic and direct dyes are recommended [33].

The main properties of textile dye effluent are color, total dissolved solids, chlorine, organic materials, toxic metals [37]. The presence of dyes results in toxic effects like skin irritation, respiratory problems on human health, and disturbing aquatic life. To overcome the trouble caused by these pollutants, we go for different treatment techniques, as mentioned in the next section [38].

The major steps involved in textile wet processing are de-sizing, scouring, bleaching, dyeing, printing, and finishing. The purpose of desizing involves removing sizing agents and effluents generated with sizing agents and effluents developed with high BOD and COD [39]. Scouring operation involves pectin and lignin removal and generates high COD [40]. Bleaching helps in improving white- 
ness and generates effluents like suspended solids [41]. Dyeing adds color to the dye by using chemicals like color, metals, and surfactants [42]. Printing and finishing are the final steps in textile wet processing, enhancing durability and generating no effluents $[43,44]$.

\section{Conventional Treatment Techniques}

As discussed in section 2, textile wastewater mainly consists of dyes, salt, sizing agent, and surfactants [45]. Based on the principle involved in the separation of textile discharge, the treatment methods are categorized into physical treatment, chemical treatment, and biological treatment methods.

\subsection{Physical Treatment}

The most commonly used physical treatment methods are adsorption, irradiation, filtration, ion-exchange, and coagulation. As there is no chemical reaction involved, these techniques require lower operating costs than chemical treatment techniques. For adsorption, adsorbents like activated carbon, silica are used [46]. In this process, a high purity product will be obtained along with secondary waste [47, 48]. Coming to ion-exchange, it is peculiar in separating desired ions. The presence of sludge and other impurities reduces the efficiency of the ion-exchange process [49, 50].

In membrane filtration, membrane clogging and high capital cost are added disadvantages [51, 52]. Electro-kinetic coagulation is highly effective in removing small particles, but excess sludge production is undesirable [53].

\subsection{Chemical Treatment}

Physical methods are not satisfactory in eradicating dye as the former requires further treatment in removing waste from textile effluent. Examples of chemical treatment include flocculation-coagulation, which is a physicochemical process. This technique helps in agglomeration, which results in the formation of colloids that can be separated from the water. Coagulation is effective in degrading insoluble dyes because of the rapid formation of colloids [54]. Another important chemical treatment technique is direct chemical oxidation. In this method, sodium hypochlorite is used to remove color from dyes [46]. Advances in chemical treatment are described in later sections. Major advantages include effective separation of impurities while disadvantages include excess sludge disposal [46].

\subsection{Biological Treatment}

Considering the ability to produce less sludge, biological treatment is the better alternative to physical and chemical treatment. If the produced wastewater contains relatively large value of COD then biological treatment is considered satisfactory for the reduction of effluents because micro-organisms employed in biological treatment have the potential to reduce COD to the lowest value [46]. Though biological treatment is not effective in decolorization, anaerobic followed by aerobic arrangement is most suitable for decolorization. Some examples include the activated sludge process, which removes biodegradable waste stabilization ponds, anae- robic reactors. Sludge disposal is a significant problem because additional cost is incurred for its removal [55].

\section{Advance Treatment Techniques}

Conventional treatment techniques are outmoded because of their lower separation efficiency. Moreover, dye molecules' biological resistance and chemical stability make it difficult to separate in traditional separation processes [56]. To increase efficiency and overcome the drawbacks of conventional treatment techniques as mentioned in the earlier section, advanced treatment techniques are used. This section of review primarily focuses on advanced oxidation processes and membrane separation processes [57-59].

\subsection{Advanced Oxidation Processes (AOPs)}

The principal goal of any AOPs is to produce and utilize hydroxyl free radical (HO). The generated free radical is a strong oxidant that is used to break compounds that conventional processes cannot oxidize. Based on this principle of generating hydroxyl free radicals, different methods have evolved to degrade effluents present in textile wastewater $[36,60]$. The major applications of AOPs include textile wastewater treatment $[36,57,59]$. The advantages and disadvantages of different AOPs are discussed in Table S2.

\subsubsection{Ozonation}

Ozone is one of the most potent oxidizing agents for the degradation of wastewater. On dissolution in water, ozone reacts with organic compounds present in wastewater by direct oxidation as $\mathrm{O}_{3}$ or by forming a hydroxyl free radical. In textile wastewater, ozone is helpful in degrading phenols and removing COD [60, 61]. The main limitation of the ozonation process is its shorter half-life period that leads to the conversion of unstable ozone to oxygen [36].

\subsubsection{Electrochemical process}

This process is highly effective in removing pollutants from textile wastewater by direct or indirect oxidation. For dyestuff containing electrodes like mercury, iron, and boron-doped diamond electrode, this method is used widely. This method requires small amounts of chemicals for the treatment, hence considered very economical $[36,60,61]$.

\subsubsection{Ozone $/ \mathrm{H}_{2} \mathrm{O}_{2}$}

The addition of $\mathrm{H}_{2} \mathrm{O}_{2}$ enhances the decomposition of $\mathrm{O}_{3}$ and the generation of hydroxyl free radicals. At acidic $\mathrm{pH}$, the reaction of $\mathrm{H}_{2} \mathrm{O}_{2}$ is significantly less with $\mathrm{O}_{3}$ because of the inadequate generation of hydroxyl free radicals. More efficiency in the generation of hydroxyl free radicals is observed at basic $\mathrm{pH}$, i.e., the maximum amount of $\mathrm{H}_{2} \mathrm{O}_{2}$ has converted to hydroxyl free radicals, which help in faster degradation of dye molecules [36, $60,62]$

\subsubsection{Fenton process}

The reaction between $\mathrm{Fe}^{2+}$ and $\mathrm{H}_{2} \mathrm{O}_{2}$ is termed Fenton's reaction. Due to the coagulation and oxidation properties of the Fenton 


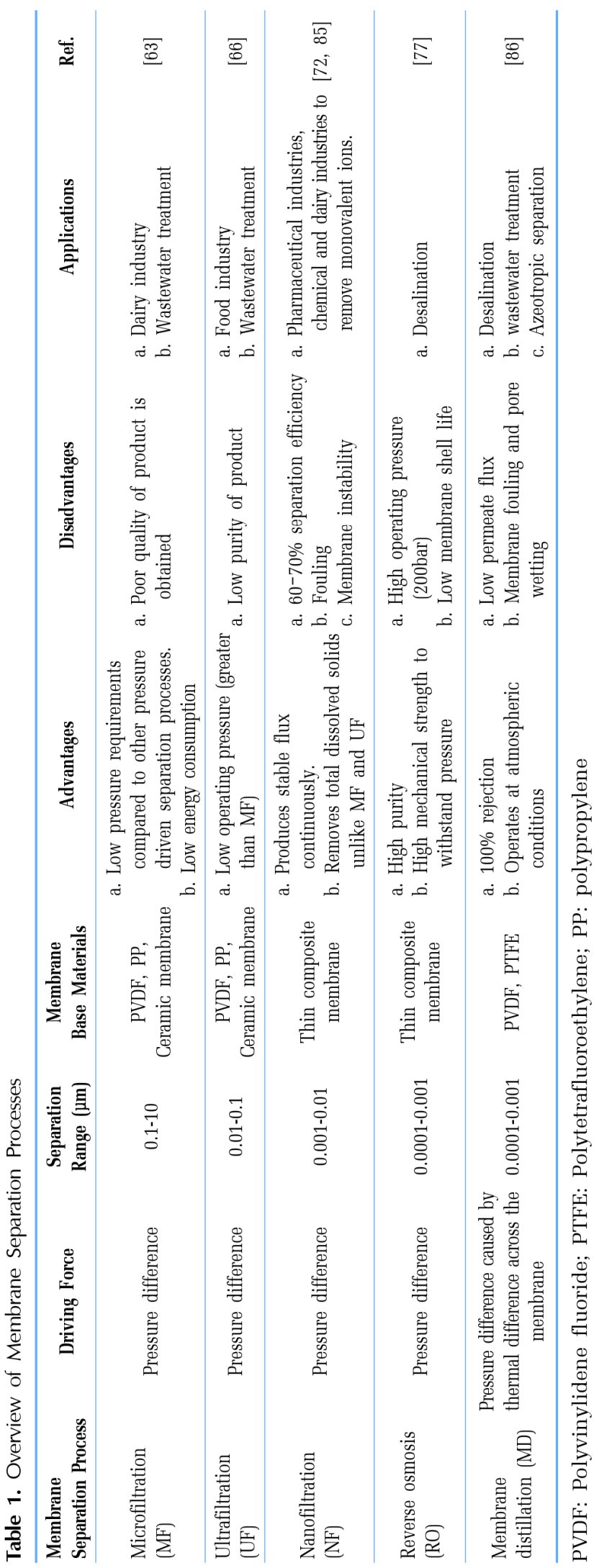

reagent, degradation of dyestuff is done using the Fenton process. The advantage of the Fenton process is that no energy is required for activating $\mathrm{H}_{2} \mathrm{O}_{2}$ conversion into hydroxyl free radicals, which in turn helps in the degradation of dyestuff [36, 54].

\subsubsection{Ozone/ $\mathrm{H}_{2} \mathrm{O}_{2} / \mathrm{UV}$}

UV process is helpful in initiating oxidizing agents like $\mathrm{H}_{2} \mathrm{O}_{2}$ and also in the degradation of dyestuff. The main advantage of this process is that no slug formation after treatment and complete decolorization of dye [60].

\subsubsection{Photo-Fenton process}

The Photo-Fenton process $\left(\mathrm{H}_{2} \mathrm{O}_{2} / \mathrm{UV} / \mathrm{Fe}^{2+}\right)$ is one of the advanced oxidation processes which involves $\mathrm{H}_{2} \mathrm{O}_{2}$ photolysis and Fenton reaction utilizing which hydroxyl free radical formation is highly increased. With the added advantage, when compared to the Fenton process, the mineralization process is highly enhanced. Efficiency in terms of decolorization is the same in both Fenton and photo-Fenton processes [54].

\subsection{Membrane Separation Processes}

The AOPs require high capital and high operating cost and also need further successive processes to put out residual oxidants present in it. The drawback mentioned above leads to the research for textile water treatment towards the membrane separation processes (MSP). Due to the no additional chemical requirement and no downstream processing, the MSP is generally considered a clean process. MSP produces good quality water and also helps in the removal of low molecular weight effluents in wastewater. MSP like microfiltration (MF) [63-65], ultrafiltration (UF) [66-68], membrane bioreactor (MBR) [69-71], nanofiltration (NF) [73, 74], reverse osmosis (RO) [23, 74, 75], and membrane distillation (MD) [76-78] are used to treat wastewater. Integrating these processes with each other helps in higher quality and better reusability of wastewater [69]. MF and UF are outdated technologies and have lower separation efficiencies in the field of textile wastewater treatment. These MSPs are integrated with NF/MD for good results [67, 79]. Except for $\mathrm{MD}$, all the MSP are pressure-driven separation processes that require relatively high pressure. As dye molecule size decreases, more pressure is applied to get permeate flux. NF gives $60-70 \%$ separation efficiency in pressure-driven separation processes while others have lower efficiencies [80-83]. To counteract these disadvantages like low efficiency and high pressure, $\mathrm{MD}$ has emerged as one of the promising membrane-based separation technologies in wastewater treatment [84]. Detailed applications, advantages, and disadvantages of MSPs are mentioned in Table 1.

\section{Membrane Distillation}

Membrane distillation can be considered an optimal solution for wastewater treatment because of its low operating pressure and low fouling tendency [87]. The conversion to potable water from contaminated water using a hydrophobic membrane at the earliest has been ascribed to Bodell [88].

$\mathrm{MD}$ is a thermally-driven separation process in which the feed 
section is separated from the permeate section by the hydrophobic porous membrane [75]. In $\mathrm{MD}$, both heat and mass transfer co-occur across the hydrophobic membrane by the phase change process [89]. The output in the permeate section is condensed by various methods like passing cold fluid, applying a vacuum, passing air followed by cold fluid, or by flowing an inert gas through the permeate side and finally gets collected. Basic $\mathrm{MD}$ configurations are classified into four, viz., direct contact membrane distillation (DCMD), air gap membrane distillation (AGMD), vacuum membrane distillation (VMD) and sweep gas membrane distillation (SGMD) [90].

The major applications of the $\mathrm{MD}$ include desalination [91-96], wastewater treatment like textile wastewater, pharmaceutical wastewater [97-100], concentration of azeotropic mixtures [101] and the concentration of aqueous solutions [86, 102].

\subsection{Direct Contact Membrane Distillation}

The DCMD is shown in Fig. 1(a) [24]. The feed section and permeate section are separated from each other by the hydrophobic membrane. The feed gets converted to vapor across the membrane. Because of the vapor pressure difference, the vapor passes through the membrane. The vapor is condensed using a low-temperature solution, preferably an aqueous solution. Because of its simplicity and high flux rate, enormous research has been done on this configuration. More conductive heat loss and difficulty of detecting wetting in the membrane are the main drawbacks of DCMD. DCMD is mainly used in desalination, wastewater treatment, the concentration of aqueous solutions, etc. [89, 103-108]. DCMD is combined with other separation technologies like $\mathrm{NF}$ and $\mathrm{RO}$ for better treatment of wastewater [3].

\subsection{Air Gap Membrane Distillation}

To limit the excessive heat loss due to membrane conduction and also to save cost for the extra condenser in SGMD, AGMD was introduced [86]. AGMD is shown in Fig. 1(b). The hot feed will contact the membrane, and the vapor formed will pass through the air gap before condensing on the cold fluid. As a result of this, heat loss and temperature polarization will be reduced. The air gap results in extra mass transfer resistance, which in turn results in lower flux than DCMD. The resistance developed is directly proportional to the width of the air gap. Any leakage or wetting of the membrane can be detected easily because of the air gap [24]. Primary applications of AGMD include desalination integrated with a renewable energy source, separation of azeotropic mixtures [109], and removal of volatile organic compounds (VOCs) from wastewater obtained from textile industries [94, 110-113].

\subsection{Vacuum Membrane Distillation}

As shown in Fig. 1(c), in VMD, vacuum is applied on the permeate side, and permeate collected outside with the help of a condenser. The principal condition for vapor suction is that the saturation pressure of molecules should be more than applied vacuum pressure. Equipment cost is hiked because of a vacuum pump and extra condenser. Because of the applied vacuum, heat loss due to conduction is minimized. Hence, the thermal efficiency of the membrane is hiked. Major applications of VMD include desalination, the concentration of aqueous solutions [86, 114, 115].

\subsection{Sweep gas Membrane Distillation}

The SGMD, shown in Fig. 1(d), is a collaboration of DCMD and AGMD as it offers low mass transfer resistance property of DCMD and low heat loss due to conduction as in the case of AGMD. Primary applications of SGMD include the removal of VOCs from wastewater, concentration of aqueous solutions, concentration of dilute glycerol wastewater [24, 27, 108].
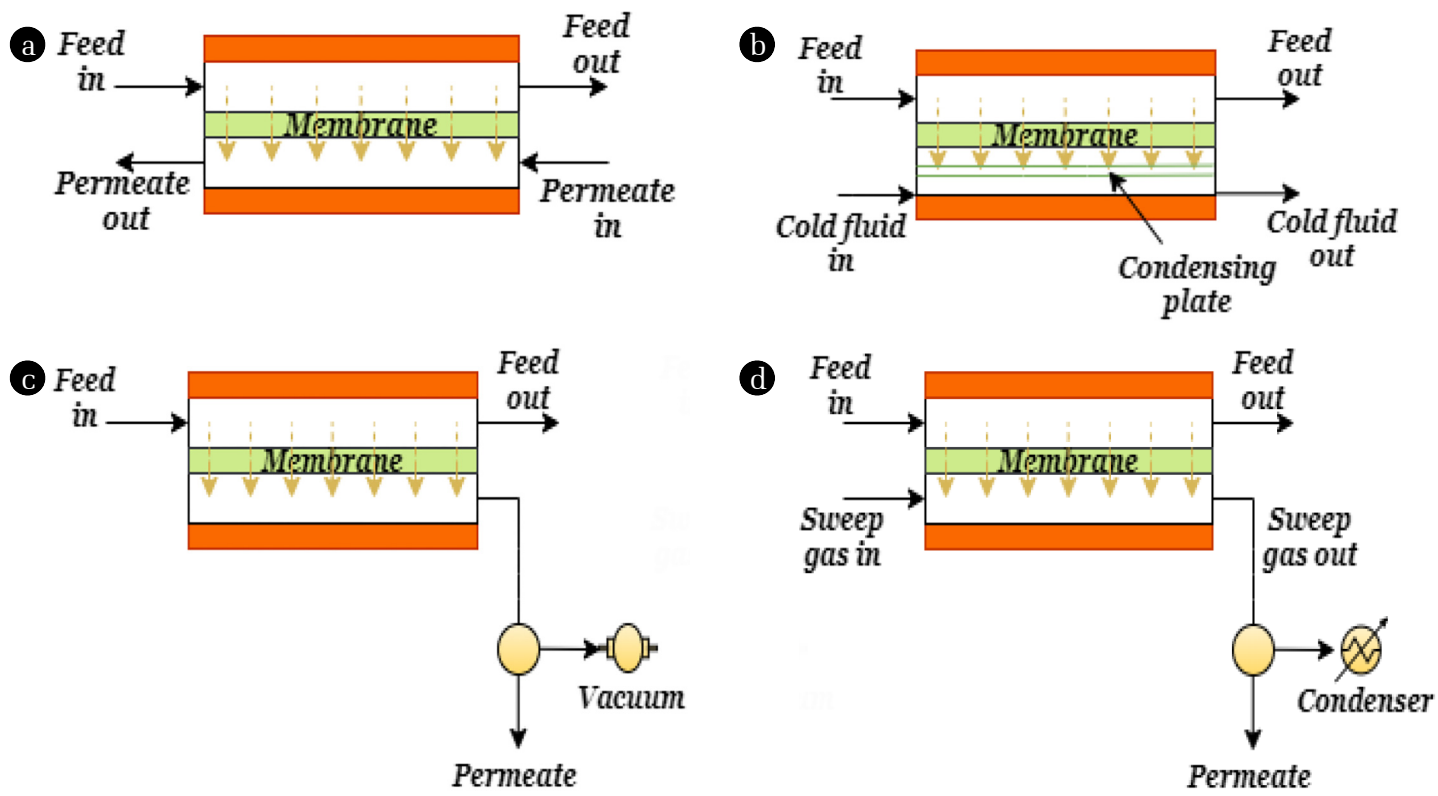

Fig. 1. Schematic of membrane distillation configurations patterned with a hydrophobic membrane. (a) Direct contact membrane distillation, (b) Air gap membrane distillation, (c) Vacuum membrane distillation, (d) Sweep gas membrane distillation. 


\section{Water Recovery and Wastewater Treatment Using the MD Process}

In textile industries, the recovery of wastewater plays a vital role in plant economics. The literature shows that $\mathrm{MD}$ gives maximum color rejection and maximum possible permeate flux [70, 116]. Fig. 2 shows the list of papers published in textile wastewater treatment with their respective year of publication. The increasing trend of the number of publications from the year 2001 to 2021 shows the continuous research work in the field of clothing industries discharged wastewater treatment using MD. In textile industries, the wastewater coming out from dyeing operation comes out at a higher temperature sufficient to enter the $\mathrm{MD}$ module [3, 50, 111, 117]. The $\mathrm{MD}$ schematic is shown in Fig. 3.

$\mathrm{Li}$ et al. [97] studied the treatment of industrial dyeing wastewater and characteristic pollutants like phenol, aniline, sulfanilic acid, 3,4-dihydroxybenzoic acid, and p-chloroaniline by DCMD. This

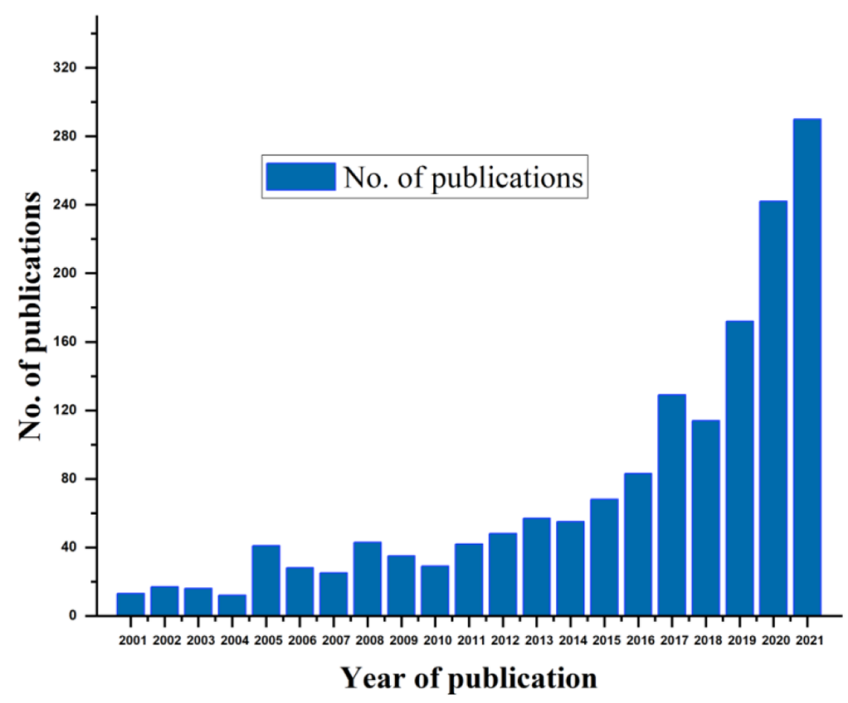

Fig. 2. The number of papers published $\mathrm{v} / \mathrm{s}$ year of publication on textile wastewater treatment using membrane distillation. Data were taken from ScienceDirect using the keyword "Textile wastewater treatment and membrane distillation" until $08^{\text {th }}$ July 2021.

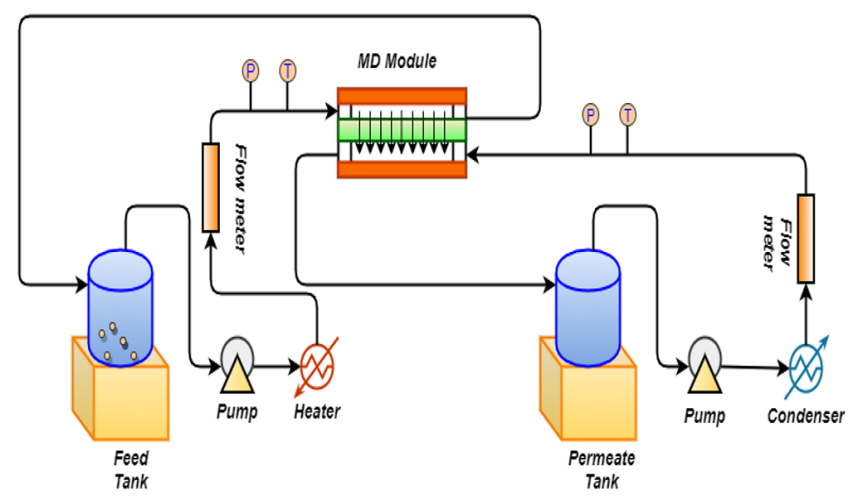

Fig. 3. Schematic diagram of membrane distillation. study also measured flux and rejection performance for PTFE and PVDF membranes. The PTFE membrane showed high flux and high rejection performance. The study also stated that the accumulation of suspended particles could be responsible for fouling and membrane wetting. The study states the DCMD process as one of the promising technologies for the treatment of dyeing wastewater. Ramlow et al. [118] studied the performance of VMD incorporated with PVDF membrane and thermopervaporation (TPV) combined with polyamide (PA) membrane for intensification of water reclamation from textile dyeing wastewater having reactive black (RB), and disperse black (DB) as the dye solutions. The study stated that the permeate flux increased in the case of VMD whereas TPV gave 100\% dye rejection for RB and DB dye solutions. This study suggested that both processes might be integrated and placed next to the dyeing machine to overcome difficulties.

Leaper et al. [119] investigated textile wastewater treatment in AGMD for dyes like sunset yellow (SY), rose bengal (RB), and surfactants like sodium dodecyl sulfate (SDS) by using commercial polyvinylidene fluoride (PVDF) membrane. This study also has compared DCMD with AGMD. For the operating time of $8 \mathrm{~h}$, the flux obtained in DCMD $\left(12.8 \mathrm{~L} / \mathrm{m}^{2} . \mathrm{h}\right)$ was more than AGMD (11 $\mathrm{L} / \mathrm{m}^{2}$.h). A 20 hour-long operating time yields complete rejection of dyes and surfactants.

Silva et al. [120] studied the evaluation of steady-state conditions for different operating times of the dyeing process obtained from textile wastewater in DCMD. A flat sheet membrane made up of PTFE was characterized as per the work done by Li et al. [97]. The operating times employed in this study are 3, 12, and 24 $\mathrm{h}$ with different dye solutions like RB and DB. The steady-state evaluation is significant because the dyeing process is a batch process. RB dyes showed a decrease of permeate flux while DB dyes showed stable permeate flux due to differences in size and ionic character. The flux variation can be classified into sub-steady, pre-steady, and steady states. As far as steady-state is concerned, the flux drops slightly with time. In the pre-steady state, the flux begins to decline until a steady-state is reached. During all experiments with RB and DB dye solutions, a high color rejection was seen, implying the reusability of recovered water. The wastewater discharged from DCMD is at $80-90^{\circ} \mathrm{C}$. The energy obtained from this can be used to heat feed the solution.

From these studies, it is evident that the performance of $\mathrm{MD}$ in textile wastewater treatment depends not only on membrane properties but also on the operating parameters employed. The main operating parameters include feed temperature, feed flow rate, permeate temperature, and concentration of textile effluents present in the feed. Table S3 represents the effect of operating parameters on $\mathrm{MD}$ performance. From the Table, it is observed that the optimum conditions are high feed temperature, high feed flow rate, low concentration of textile effluents, and low permeate temperature.

Table 2 illustrates various studies done in the field of textile wastewater treatment using MD. These studies quoted that $100 \%$ color rejection of dye is possible, and permeate flux obtained was less. Recovery of wastewater is high and can be further increased by using hybrid membrane separation processes. 


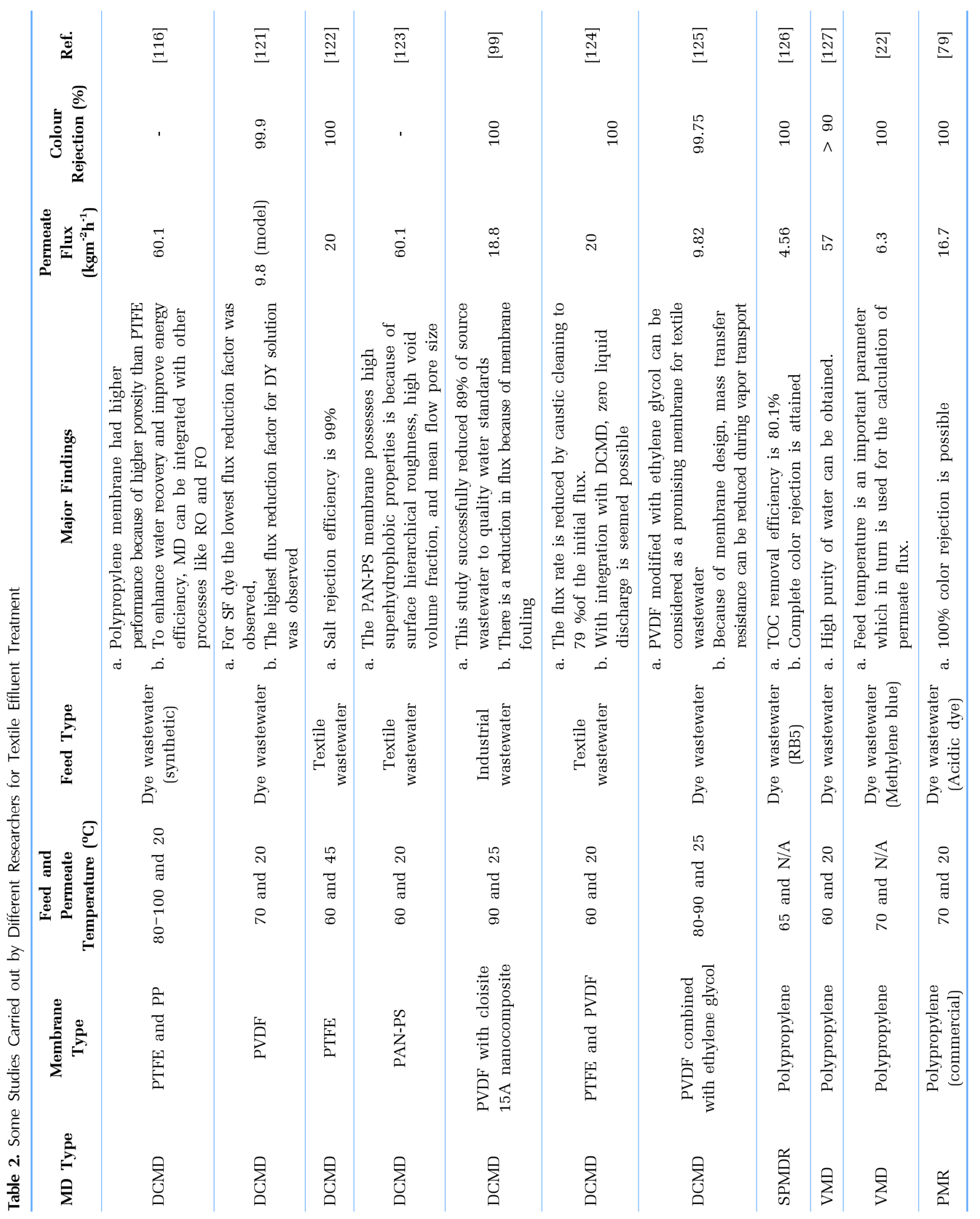




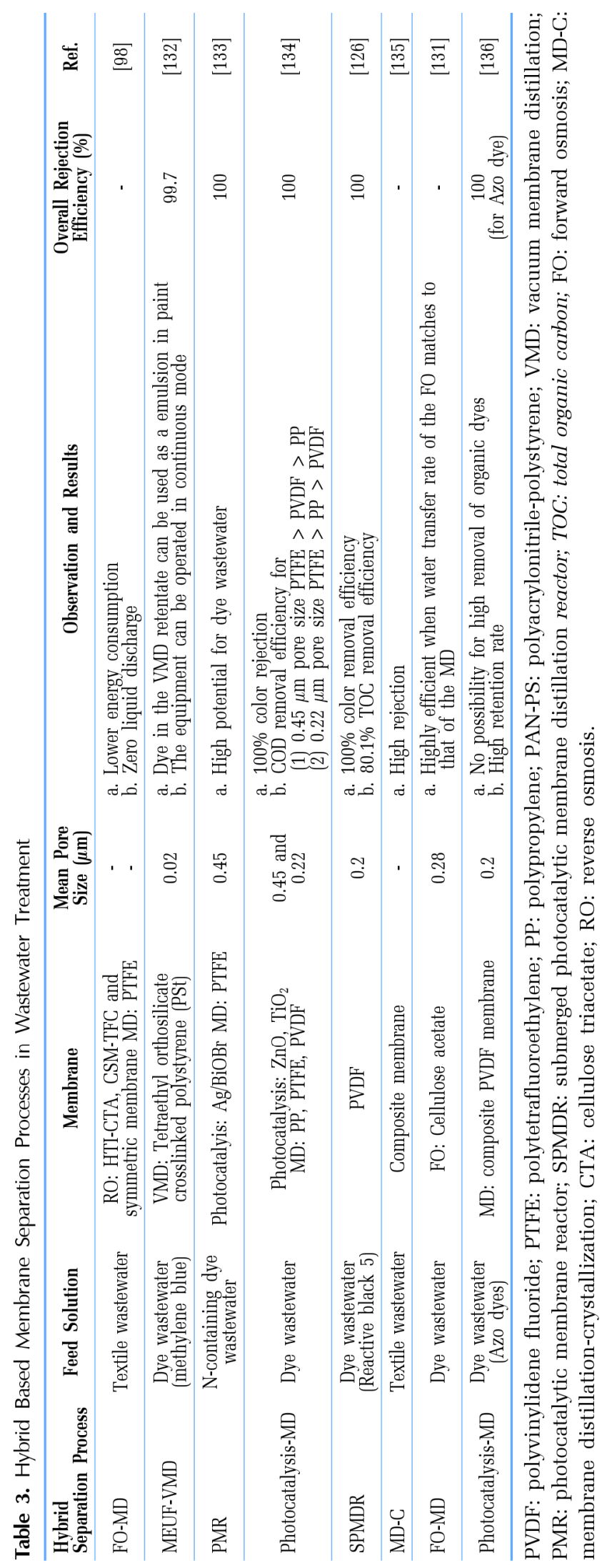

\section{Hybrid Separation Processes Based on MD in Wastewater Treatment}

Membrane distillation offers many advantages when compared with conventional separation processes. Despite having many benefits, the process has several limitations when used individually. Hence, the need for membrane-based hybrid separation processes came into existence. These membrane-based hybrid separation processes overcome the limitations of $\mathrm{MD}$ like performance at high concentrations of wastewater to the maximum extent and enhance the water recovery [90, 128-130]. Membrane-based hybrid separation processes are classified into two categories [129], viz., (i) Membrane process integrated with conventional separation process $(\mathrm{MCH})$, which is generally applied to minimize capital costs and (ii) Membrane process integrated with other membrane separation process $(\mathrm{MMH})$, which is used to overcome the limitations occurring in the membrane separation process.

Some of the MD-based hybrid separation processes are forward osmosis-membrane distillation (FO-MD), membrane distillationcrystallization (MD-C), micellar enhanced ultrafiltration- membrane distillation (MEUF-MD), and photocatalysis-membrane reactor (PMR). Ge et al. [131] studied polyelectrolyte-promoted hybrid FO-MD for dye wastewater treatment to enhance water permeate flux and increase water recovery. This hybrid combination has greater potential than the $\mathrm{MD}$ process alone. Table 3 shows various studies reported by different researchers in the field of hybrid separation processes. These studies show that hybrid separation processes have greater potential for wastewater treatment and stand as a promising technology in wastewater treatment.

\section{MD Membrane Fouling}

Fouling is a phenomenon that happens because of the accumulation of unwanted materials on the membrane surface. Fouling causes a reduction in permeate flux and irregular performance of separation. In textile wastewater treatment, fouling occurs because of dyes, effluents, and surfactants present in the wastewater. They block the pores of the membrane resulting in a decline of flux [3, 122]. Common types of fouling that happen in the membrane systems are inorganic fouling (most commonly known as scaling), organic fouling, and biological fouling (biofouling) [86, 93, 103, 121, 137-139]. Inorganic fouling is prominently caused by alkaline salts, particulate matter, and other uncharged molecules. Organic fouling is referred to as natural organic matter. Organic fouling is caused by proteins, polysaccharides, organic acids, humic substances, etc. Both organic and inorganic fouling increases with the increase in both feed temperature and pressure drop. The fidelity of micro-organisms and the formation of the biofilm layer are generally referred to as bio-fouling. Bio-fouling increases with temperature up to $30-40^{\circ} \mathrm{C}$. Upon increasing temperature, micro-organisms responsible for bio-fouling will die. Bio-fouling helps in the reduction of permeate flux to some extent [24, 139, 140]. 


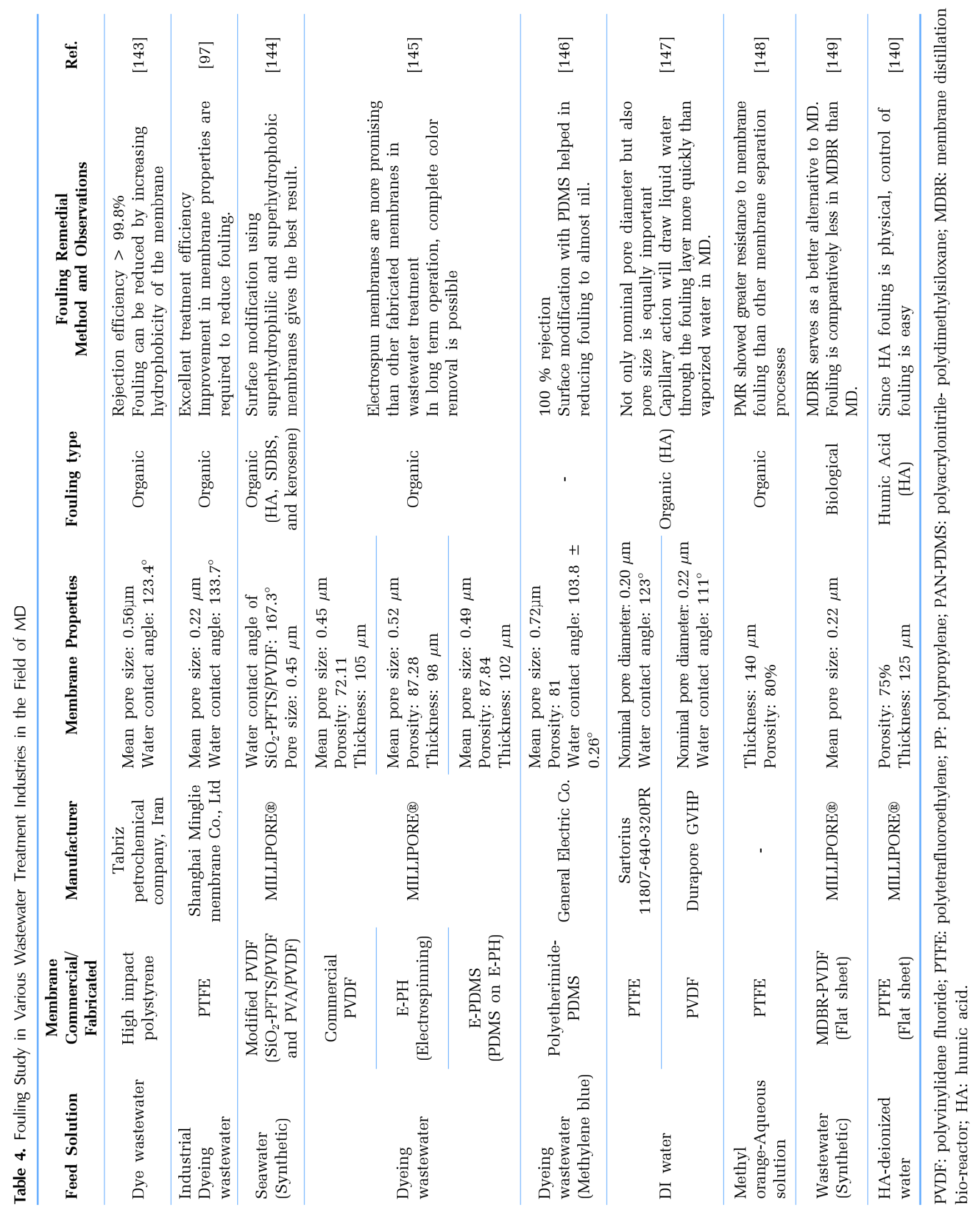




\subsection{Effect of Driving Force on Membrane Fouling}

The formation of a fouling layer on the membrane surface results in decrease of temperature difference across the membrane. As a result, temperature polarization increases. As a result, the driving force decreases, and permeate flux obtained will be lower than the pure membrane. Fig. S2 represents fouling areas on the membrane. Surface fouling refers to fouling present on the membrane surface, which is reversible and can be cleaned by chemical cleaning. Chemical cleaning refers to the addition of cleansing agents like EDTA to weaken the bond between foulants and membrane surfaces. This significantly helps in removing surface fouling. Continuous chemical cleaning can damage membrane morphology and membrane stability by altering physical and chemical properties of membrane thereby reducing rejection. To minimize membrane cleaning and enhance membrane stability, polymeric membranes should be doped with self-cleaning activity materials. Among these self-cleaning materials, materials having photocatalytic activity are widely used since they can neutralize fouling by using a photocatalytic property when exposed to sunlight [141]. Internal fouling refers to the presence of foulants inside the membrane pores. These block the pathway of vapor molecules across the membrane and lead to permanent damage of the membrane. To minimize this, surface modification techniques are widely employed and are discussed in the next section.

Fortunato et al. [142] investigated synthetic dye wastewater (congo red) on membrane performance and fouling using DCMD. The results exhibited $100 \%$ rejection at all experimental conditions. The author stated that the thickness of the fouling layer increased along the membrane length because of the variation of driving force over the membrane length. Some other literature in the field of membrane fouling is shown in Table 4. These observations quote that membrane fouling is a drawback of MD. The next section focuses on the minimization of fouling by using surface modification techniques.

\section{Membrane Fabrication and Modification}

The hottest area of research in MD is membrane fabrication and its modification. The available commercial membranes lack in terms of performance, fouling resistance, and wetting resistance. To overcome these shortcomings, the need for membrane fabrication and modification is necessary. Many studies have been reported on membrane morphology, geometry, pore size, and thickness of the membrane [102]. Hydrophobic membranes are chosen due to their easiness of membrane fabrication and modification. Fabrication methods employed to fabricate are nonsolvent induced phase separation (NIPS), thermally induced phase separation (TIPS), sintering, electro-spinning, and melt extrusion spinning [95, 100, 150-155]. Surface modification methods include grafting (chemical grafting, plasma grafting, photo grafting, and thermal grafting) and surface coating [102].

The mainly used commercial membranes in MD are PVDF, PTFE, and PP. The PTFE, being a non-polar polymer, cannot be fabricated by NIPS and TIPS methods. Hence, the methods used for fabricating PTFE are sintering and melt extrusion methods [156, 157]. The

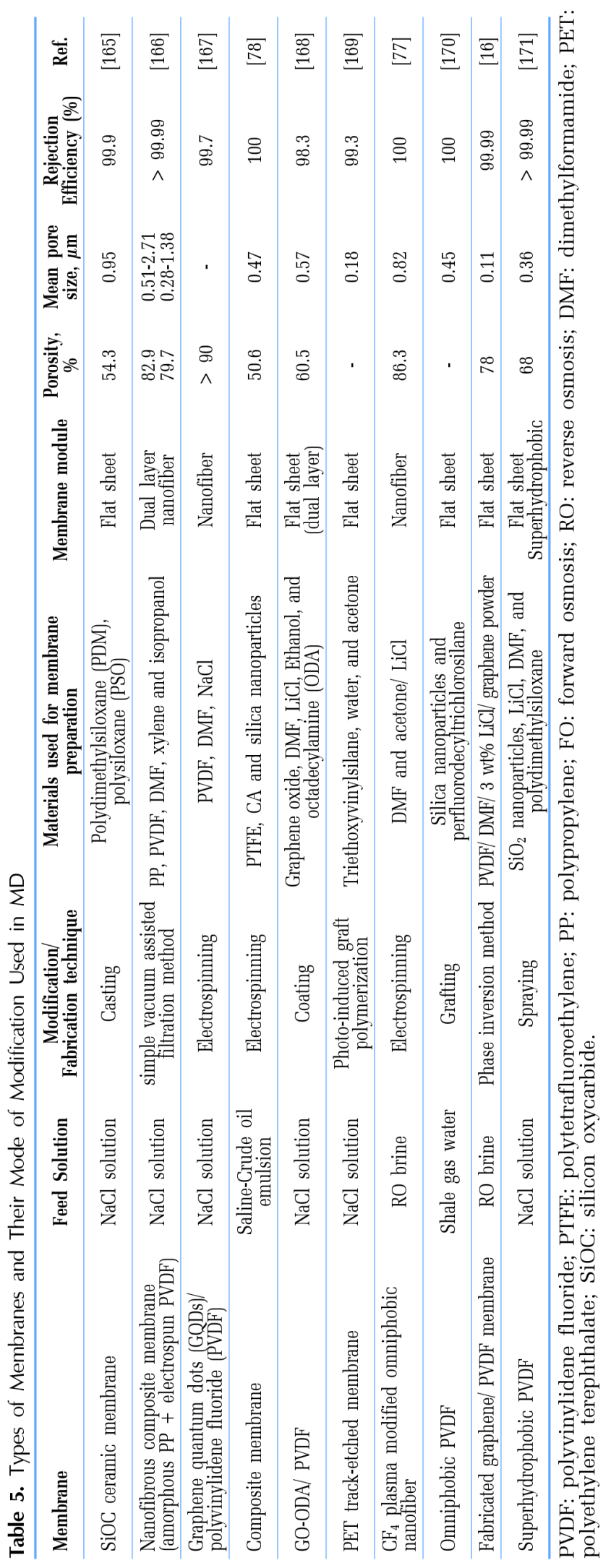


PP can be fabricated from TIPS and melt extrusion methods because of its sits elastic properties [158, 159]. The PVDF membrane can be fabricated from both TIPS and NIPS or a combination of both because of its solubility in dimethylformamide (DMF) and dimethylacetamide (DMAC) [160].

Camacho et al. [161] fabricated different hydrophobic membranes like PTFE, PP, and PVDF based on different fabrication methods with varying sizes of pore. The PTFE membranes are prepared using a sintering technique with porosity ranging from $10 \%$ to $40 \%$ and pore size of range 0.2 to $20 \mu \mathrm{m}$. The PP and PTFE membranes are also fabricated from stretching technology with porosity around $90 \%$ and pore size ranging from 0.2 to 20 $\mu \mathrm{m}$. The PVDF membranes are manufactured by using the phase inversion technique. The membrane prepared has a porosity of about $80 \%$ and pore size ranging from 0.2 to $20 \mu \mathrm{m}$.

Hendren et al. [162] studied surface modification of nanostructured ceramic membranes for DCMD. The alumina anodic membranes are modified and turned into hydrophobic using perfluorodecyltriethyoxysilane (PFS) and trichloromethylsilane (TCS) by using the grafting technique. The studies stated that PFS treated membrane showed a more steady-state flux than membrane treated with TCS. Wang et al. [163] fabricated a composite membrane for MD to resist oil fouling. The authors modified a commercial hydrophobic PVDF membrane with nanocomposite materials like silica nanoparticles, chitosan hydrogel, and fluoro-polymer as shown in Fig. S3. The figure shows that the modified membrane displayed different surface morphology compared to commercial membrane due to the presence of nanocomposite coating. Also, the modified membrane exhibited asymmetric wettability with a modified surface resistant to oil fouling, and the other unmodified surface remained hydrophobic. The modified membrane is compared with the new PVDF membrane, which stated that the composite membrane exhibited better resistance towards oil resistance. Liao et al. [164] fabricated electro-spun superhydrophobic dual-layer membranes for MD. These membranes exhibited superhydrophobicity and showed resistance towards emulsions and salty water. These membranes showed high mechanical strength and are durable in $\mathrm{MD}$ operations. Table 5 shows different membranes along with their mode of modification. The observations from this section show that membrane porosity is increased, and membrane wetting is decreased because of membrane modification.

\section{Conclusions}

Membrane distillation has been used for the purification of the different types of wastewater like oily wastewater, dye mixture containing wastewater, salt included wastewater, etc. However, $\mathrm{MD}$ was found very successful in textile wastewater treatment, but the membrane fouling and wetting encountered during the operation are major concerns. Therefore, the development of fouling resisting membrane is a crucial point in MD's future research direction. Thus, the present review highlights the different aspects of textile wastewater treatment using $\mathrm{MD}$ starting from textile effluents to the recent advancement of membrane modification. Other types of conventional treatment techniques and their merits and demerits are also discussed. Along with the types of MD config- uration, the membrane fouling study has also been explored. The present review also focuses on the recent advancements in membrane modification and fabrication technology which helped in significantly reducing membrane fouling and membrane wetting, making membrane withstand for an extended period.

Nowadays, the membrane distillation process is gaining wide attention in wastewater treatment for high water recovery. The thermal energy requirement for heating feed and lower permeate flux makes it difficult for long-term operations in industries. To overcome these situations, $\mathrm{MD}$ is combined with other membrane separation processes to treat wastewater. As discussed in the current review, these hybrid-based membrane separation processes help improve permeate flux and enhance water recovery, making 100\% separation possible.

\section{Author Contributions}

A.S.R. (Master Student) has done the scientific literature review and written the manuscript along with Figures and Tables. S.K. (Assistant Professor) has revised and corrected the manuscript. Z.V.P.M (Professor) edited and added some important parts to the final manuscript.

\section{References}

1. Pangarkar BL, Deshmukh SK, Thorat PV. Pesticide Wastewater Pollution and Treatment Methods: Review. Chem. Sci. Rev. Lett. 2014;3:374-380.

2. Kumar R, Singh RD, Sharma KD. Water resources of India. Curr. Sci. 2005;89:794-811.

3. Dow N, Villalobos García J, Niadoo L, et al. Demonstration of membrane distillation on textile waste water assessment of long term performance, membrane cleaning and waste heat integration. Environ. Sci. Water Res. Technol. 2017;3:433-449.

4. Volmajer Valh J, Majcen Le Marechal A, Vajnhandl S, et al. Water in the Textile Industry. In: Treatise on Water Science; 2011. p. 685-706.

5. Plattner J, Kazner C, Naidu G, et al. Removal of selected pesticides from groundwater by membrane distillation. Environ. Sci. Pollut. Res. 2018;25:20336-20347.

6. Plattner JG. Membrane Distillation for the Removal of Fluoride and Pesticides in Remote Areas in India [dissertation]. University of Technology Sydney; 2017.

7. Tibi F, Charfi A, Cho J, et al. Fabrication of polymeric membranes for membrane distillation process and application for wastewater treatment: Critical review. Process Saf. Environ. Prot. 2020;141:190-201.

8. Nasir A, Masood F, Yasin T, et al. Progress in polymeric nanocomposite membranes for wastewater treatment: Preparation, properties and applications. J. Ind. Eng. Chem. 2019;79:29-40.

9. Pavithra KG, P. SK, Jaikumar V, et al. Removal of colorants from wastewater: A review on sources and treatment strategies. J. Ind. Eng. Chem. 2019;75:1-19.

10. Neoh CH, Noor ZZ, Mutamim NSA, et al. Green technology in wastewater treatment technologies: Integration of membrane 
bioreactor with various wastewater treatment systems. Chem. Eng. J. 2016;283:582-594.

11. Jegatheesan V, Pramanik BK, Chen J, et al. Treatment of textile wastewater with membrane bioreactor: A critical review. Bioresour. Technol. 2016;204:202-212.

12. Shirazi MMA, Kargari A. A review on applications of membrane distillation (MD) process for wastewater treatment. J. Membr. Sci. Res. 2015;1:101-112.

13. Madalosso HB, de Sousa Silva R, Merlini A, et al. Modeling and experimental validation of direct contact membrane distillation applied to synthetic dye solutions. J. Chem. Technol. Biotechnol. 2021;96:909-922.

14. Nthunya LN, Gutierrez L, Lapeire L, et al. Fouling-resistant PVDF nanofibre membranes for the desalination of brackish water in membrane distillation. Sep. Purif. Technol. 2019;228: 115793.

15. Seyed Shahabadi SM, Rabiee H, Seyedi SM, et al. Superhydrophobic dual layer functionalized titanium dioxide/polyvinylidene fluoride-co-hexafluoropropylene (TiO2/PH) nanofibrous membrane for high flux membrane distillation. J. Memb. Sci. 2017;537:140-150.

16. Woo YC, Kim Y, Shim WG, et al. Graphene/PVDF flat-sheet membrane for the treatment of RO brine from coal seam gas produced water by air gap membrane distillation. J. Memb. Sci. 2016;513:74-84.

17. Balati A, Wagle D, Nash KL, et al. Heterojunction of TiO2 nanoparticle embedded into ZSM5 to 2D and 3D layered-structures of MoS2 nanosheets fabricated by pulsed laser ablation and microwave technique in deionized water: structurally enhanced photocatalytic performance. Appl. Nanosci. 2019;9:19-32.

18. Balati A, Bazilio A, Shahriar A, et al. Simultaneous formation of ultra-thin MoSe2 nanosheets, Inorganic Fullerene-Like MoSe2 and MoO3 quantum dots using fast and ecofriendly Pulsed Laser Ablation in Liquid followed by microwave treatment. Mater. Sci. Semicond. Process 2019;99:68-77.

19. Balati A, Matta A, Nash K, et al. Heterojunction of vertically aligned MoS2 layers to Hydrogenated Black $\mathrm{TiO}_{2}$ and Rutile Based Inorganic Hollow Microspheres for the highly enhanced visible light arsenic photooxidation. Compos. Part B. Eng. 2020;185:107785.

20. Balati A, Tek S, Nash K, et al. Nanoarchitecture of TiO 2 microspheres with expanded lattice interlayers and its heterojunction to the laser modified black TiO 2 using pulsed laser ablation in liquid with improved photocatalytic performance under visible light irradiation. J. Colloid. Interface. Sci. 2019;541:234-248.

21. Babu J, Murthy ZVP. Treatment of textile dyes containing wastewaters with PES/PVA thin film composite nanofiltration membranes. Sep. Purif. Technol. 2017;183:66-72.

22. Banat F, Al-Asheh S, Qtaishat M. Treatment of waters colored with methylene blue dye by vacuum membrane distillation. Desalination 2005;174:87-96.

23. Dhodapkar RS, Pophali GR, Nandy T, et al. Exploitation results of seven RO plants for recovery and reuse of treated effluents in textile industries. Desalination 2007;217:291-300.

24. Kalla S, Upadhyaya S, Singh K. Principles and advancements of air gap membrane distillation. Rev. Chem. Eng. 2019;35:817859.
25. Baghel R, Kalla S, Upadhyaya S, et al. Treatment of Sudan III Dye from wastewater using Vacuum Membrane Distillation. J. Basic Appl. Eng. Res. 2017;4:237-241.

26. Baghel R, Upadhyaya S, Chaurasia SP, et al. Optimization of process variables by the application of response surface methodology for naphthol blue black dye removal in vacuum membrane distillation. J. Clean. Prod. 2018;199:900-915.

27. Souhaimi MK, Matsuura T. Membrane Distillation. Membr. Distill. 2011;124:1-25.

28. Goh PS, Matsuura T, Ismail AF, et al. Recent trends in membranes and membrane processes for desalination. Desalination 2016;391:43-60.

29. World Trade Organization. The Future of Services Trade. Geneve: World Trade Organization. WTO publications; 2019.

30. Sheng L. WTO Reports World Textile and Apparel Trade in 2018. FASH455 Glob. Appar Text Trade Sourc 2019 [Internet]. [cited 2 May, 2021]. Available from: https://shenglufashion.com/ 2019/08/16/wto-reports-world-textile-and-apparel-trade-in2018/

31. Chhonkar PK, Datta SP, Joshi HC, et al. Impact of industrial effluents on soil health and agriculture -Indian experience: Part II-tannery and textile industrial effluents. J. Sci. Ind. Res. (India) 2000;59:446-454.

32. Bledzki A, Gassan J. Composites reinforced with cellulose. Prog. Polym. Sci. 1999;24:221-274.

33. $\mathrm{R}$ Ananthashankar AG. Production, Characterization and Treatment of Textile Effluents: A Critical Review. J. Chem. Eng. Process Technol. 2013;05:1-18.

34. Senthil Kumar P, Saravanan A. Sustainable wastewater treatments in textile sector. Sustain Fibres Text 2017;323-346.

35. Carmen Z, Daniela S. Textile Organic Dyes - Characteristics, Polluting Effects and Separation/Elimination Procedures from Industrial Effluents - A Critical Overview. Dr. Tomasz Puzyn ed. Organic Pollutants Ten Years After the Stockholm Convention - Environmental and Analytical Update. InTech: 2012. p. 55-86.

36. Gosavi VD, Sharma S. A General Review on Various Treatment Methods for Textile Wastewater. J. Environ. Sci. Computer Sci. Eng. Technol. 2014;3:29-39.

37. Turhan K, Durukan I, Ozturkcan SA, et al. Decolorization of textile basic dye in aqueous solution by ozone. Dyes Pigm. 2012;92:897-901.

38. Hasanpour M, Hatami M. Photocatalytic performance of aerogels for organic dyes removal from wastewaters: Review study. J. Mol. Liq. 2020;309:113094.

39. Holkar CR, Jadhav AJ, Pinjari DV, et al. A critical review on textile wastewater treatments: Possible approaches. J. Environ. Manage 2016;182:351-366.

40. Yaseen DA, Scholz M. Textile dye wastewater characteristics and constituents of synthetic effluents: a critical review. Springer Berlin Heidelberg; 2019.

41. Kabir SMF, Chakraborty S, Hoque SMA, et al. Sustainability Assessment of Cotton-Based Textile Wet Processing. Clean. Technol. 2019;1:232-246.

42. Correia VM, Stephenson T, Judd SJ. Characterisation of textile wastewaters - a review. Environ Technol (United Kingdom) 1994;15:917-929. 
43. Taylor P, Bisschops I, Spanjers H. Literature review on textile wastewater characterisation. Environ. Technol. 2008;37-41.

44. Hussain T, Wahab A. A critical review of the current water conservation practices in textile wet processing. J. Clean. Prod. 2018;198:806-819.

45. Gopalakrishnan K, Manivannan V, Jeyadoss T. Comparative study on biosorption of $\mathrm{Zn}(\mathrm{II}), \mathrm{Cu}(\mathrm{II})$ and $\mathrm{Cr}(\mathrm{VI})$ from textile dye effluent using sawdust and neem leaves powder. J. Chem. 2010;7:504-511.

46. Singh K, Arora S. Removal of synthetic textile dyes from wastewaters: A critical review on present treatment technologies. Crit. Rev. Environ. Sci. Technol. 2011;41:807-878.

47. Choy KKH, McKay G, Porter JF. Sorption of acid dyes from effluents using activated carbon. Resour. Conserv. Recycl. 1999;27:57-71.

48. Robinson T, McMullan G, Marchant R, et al. Remediation of dyes in textile effluent: A critical review on current treatment technologies with a proposed alternative. Bioresour. Technol. 2001;77:247-255.

49. Iqbal MJ, Ashiq MN. Adsorption of dyes from aqueous solutions on activated charcoal. J. Hazard. Mater. 2007;139:57-66.

50. Dasgupta J, Sikder J, Chakraborty S, et al. Remediation of textile effluents by membrane based treatment techniques: A state of the art review. J. Environ. Manage 2015;147:55-72.

51. Mishra G, Tripathy M. A critical review of the treatments for decolourization of textile effluent. Colourage 1993;40:35-38.

52. Xu Y, Lebrun RE, Gallo PJ, et al. Treatment of textile dye plant effluent by nanofiltration membrane. Sep. Sci. Technol. 1999;34:2501-2519.

53. Gahr F, Hermanutz F, Oppermann W. Ozonation - An important technique to comply with new German laws for textile wastewater treatment. Water Sci. Technol. 1994;30:255-263.

54. Kang SF, Liao CH, Po ST. Decolorization of textile wastewater by photo-fenton oxidation technology. Chemosphere 2000;41: 1287-1294.

55. Fukushima M, Tatsumi K, Morimoto K. The fate of aniline after a photo-Fenton reaction in an aqueous system containing iron(III), humic acid, and hydrogen peroxide. Environ. Sci. Technol. 2000;34:2006-2013.

56. Kaur P, Kushwaha JP, Sangal VK. Transformation products and degradation pathway of textile industry wastewater pollutants in Electro-Fenton process. Chemosphere 2018;207:690-698.

57. Mazivila SJ, Ricardo IA, Leitão JMM, et al. A review on advanced oxidation processes: From classical to new perspectives coupled to two- and multi-way calibration strategies to monitor degradation of contaminants in environmental samples. Trends Environ. Anal. Chem. 2019;24:1-10.

58. Paździor K, Bilińska L, Ledakowicz S. A review of the existing and emerging technologies in the combination of AOPs and biological processes in industrial textile wastewater treatment. Chem. Eng. J. 2019;376:120597.

59. Babu DS, Srivastava V, Nidheesh PV, et al. Detoxification of water and wastewater by advanced oxidation processes. Sci. Total Environ. 2019;696:133961.

60. Al-Kdasi A, Idris A, Saed K, et al. Treatment of textile wastewater by advanced oxidation processes- A review. Glob. Nest J. 2004;6:222-230.
61. Baig S, Liechti PA. Ozone treatment for biorefractory COD removal. Water Sci. Technol. 2001;43:197-204.

62. Ledakowicz S, Solecka M, Zylla R. Biodegradation, decolourisation and detoxification of textile wastewater enhanced by advanced oxidation processes. J. Biotechnol. 2001;89:175-184.

63. Abadi SRH, Sebzari MR, Hemati M, et al. Ceramic membrane performance in microfiltration of oily wastewater. Desalination 2011;265:222-228.

64. Tahri N, Jedidi I, Cerneaux S, et al. Development of an asymmetric carbon microfiltration membrane: Application to the treatment of industrial textile wastewater. Sep. Purif Technol. 2013;118:179-187.

65. Campos JC, Borges RMH, Oliveira Filho AM, et al. Oilfield wastewater treatment by combined microfiltration and biological processes. Water Res. 2002;36:95-104.

66. Lin J, Ye W, Baltaru MC, et al. Tight ultrafiltration membranes for enhanced separation of dyes and Na2SO4 during textile wastewater treatment. J. Membr. Sci. 2016;514:217-228.

67. Vergili I, Kaya Y, Sen U, et al. Techno-economic analysis of textile dye bath wastewater treatment by integrated membrane processes under the zero liquid discharge approach. Resour. Conserv. Recycl. 2012;58:25-35.

68. Thamaraiselvan C, Noel M. Membrane processes for dye wastewater treatment: Recent progress in fouling control. Crit Rev Environ. Sci. Technol. 2015;45:1007-1040.

69. Fonseca Couto C, Lange LC, Santos Amaral MC. A critical review on membrane separation processes applied to remove pharmaceutically active compounds from water and wastewater. J. Water Process Eng. 2018;26:156-175.

70. Yurtsever A, Sahinkaya E, Çınar Ö. Performance and foulant characteristics of an anaerobic membrane bioreactor treating real textile wastewater. J. Water Process Eng. 2020;33:101088.

71. Quist-Jensen CA, Macedonio F, Drioli E. Membrane technology for water production in agriculture: Desalination and wastewater reuse. Desalination 2015;364:17-32.

72. Jhaveri JH, Murthy ZVP. A comprehensive review on anti-fouling nanocomposite membranes for pressure driven membrane separation processes. Desalination 2016;379:137-154.

73. Sahinkaya E, Uzal N, Yetis U, et al. Biological treatment and nanofiltration of denim textile wastewater for reuse. J. Hazard. Mater. 2008;153:1142-1148.

74. Pangarkar BL, Sane MG, Guddad M. Reverse Osmosis and Membrane Distillation for Desalination of Groundwater: A Review. ISRN Mater. Sci. 2011;2011:1-9.

75. Van Der Bruggen B, Lejon L, Vandecasteele C. Reuse, treatment, and discharge of the concentrate of pressure-driven membrane processes. Environ. Sci. Technol. 2003;37:3733-3738.

76. Tijing LD, Choi J, Lee S, et al. Recent progress of membrane distillation using electrospun nano fibrous membrane. J. Membr. Sci. 2014;453:435-462.

77. Woo YC, Chen Y, Tijing LD, et al. CF4 plasma-modified omniphobic electrospun nanofiber membrane for produced water brine treatment by membrane distillation. J. Membr. Sci. 2017;529:234-242.

78. Hou D, Wang Z, Wang K, et al. Composite membrane with electrospun multiscale-textured surface for robust oil-fouling resistance in membrane distillation. J. Membr. Sci. 2018;546: 
179-187.

79. Mozia S, Tomaszewska M, Morawski AW. A new photocatalytic membrane reactor (PMR) for removal of azo-dye Acid Red 18 from water. Appl. Catal. B Environ. 2005;59:131-137.

80. Ong YK, Li FY, Sun SP, et al. Nanofiltration hollow fiber membranes for textile wastewater treatment: Lab-scale and pilot-scale studies. Chem. Eng. Sci. 2014;114:51-57.

81. Gwak G, Hong S. Draw solute selection. In: Membrane-Based Salinity Gradient Processes for Water Treatment and Power Generation. 2018. p. 87-122.

82. Ji D, Xiao C, An S, et al. Preparation of high-flux PSF/GO loose nanofiltration hollow fiber membranes with dense-loose structure for treating textile wastewater. Chem. Eng. J. 2019;363 33-42.

83. Ciardelli G, Corsi L, Marcucci M. Membrane separation for wastewater reuse in the textile industry. Resour. Conserv. Recycl. 2001;31:189-197.

84. Dotremont C, Kregersman B, Sih R, et al. Seawater desalination with memstill technology - a sustainable solution for the industry. Water Pract. Technol. 2010;5(2):1-7.

85. Oatley-Radcliffe DL, Walters M, Ainscough TJ, et al. Nanofiltration membranes and processes: A review of research trends over the past decade. J. Water Process Eng. 2017;19: 164-171.

86. Chang YS, Leow HTL, Ooi BS. Membrane distillation for water recovery and its fouling phenomena. J. Membr. Sci. Res. 2020;6:107-124.

87. Mokhtar NM, Lau WJ, Goh PS. Effect of hydrophobicity degree on PVDF hollow fiber membranes for textile wastewater treatment using direct contact membrane distillation. J. Teknol. (Sci. Eng.) 2013;65:77-81.

88. Bodell BR. Distillation of Saline Water Using Silicone Rubber Membrane. United States Patent, no. 3,361,645; 1968. p. 1-4.

89. Cath TY, Adams VD, Childress AE. Experimental study of desalination using direct contact membrane distillation: A new approach to flux enhancement. J. Membr. Sci. 2004;228:5-16.

90. Wang P, Chung TS. Recent advances in membrane distillation processes: Membrane development, configuration design and application exploring. J. Membr. Sci. 2015;474:39-56.

91. Tijing LD, Woo YC, Choi JS, et al. Fouling and its control in membrane distillation-A review. J. Membr. Sci. 2015;475: 215-244.

92. Warsinger DM, Servi A, Van Belleghem S, et al. Combining air recharging and membrane superhydrophobicity for fouling prevention in membrane distillation. J. Membr. Sci. 2016;505: 241-252.

93. Warsinger DM, Swaminathan J, Guillen-Burrieza E, et al. Scaling and fouling in membrane distillation for desalination applications: A review. Desalination 2015;356:294-313.

94. Alkhudhiri A, Hilal N. Air gap membrane distillation: A detailed study of high saline solution. Desalination 2017;403:179-186.

95. Fang H, Gao JF, Wang HT, et al. Hydrophobic porous alumina hollow fiber for water desalination via membrane distillation process. J. Membr. Sci. 2012;403-404:41-46.

96. Hanemaaijer JH. Memstill ${ }^{\circledR}$ - Low cost membrane distillation technology for seawater desalination. Desalination 2004;168:355.

97. Li F, Huang J, Xia Q, et al. Direct contact membrane distillation for the treatment of industrial dyeing wastewater and characteristic pollutants. Sep. Purif Technol. 2018;195:83-91.

98. Li M, Li K, Wang L, et al. Feasibility of concentrating textile wastewater using a hybrid forward osmosis-membrane distillation (FO-MD) process: Performance and economic evaluation. Water Res. 2020;172:115488.

99. Mokhtar NM, Lau WJ, Ismail AF, et al. The potential of direct contact membrane distillation for industrial textile wastewater treatment using PVDF-Cloisite 15A nanocomposite membrane. Chem. Eng. Res. Des. 2016;111:284-293.

100. Tomaszewska M. Industrial wastewater treatment by means of membrane techniques. Polish J. Chem. Technol. 2007;9: 138-142.

101. Kalla S, Upadhyaya S, Singh K, et al. Development of heat and mass transfer correlations and recovery calculation for HCl-water azeotropic separation using air gap membrane distillation. Chem. Pap 2019;73:2449-2460.

102. Krajewski SR, Kujawski W, Bukowska M, et al. Application of fluoroalkylsilanes (FAS) grafted ceramic membranes in membrane distillation process of $\mathrm{NaCl}$ solutions. J. Membr. Sci. 2006;281:253-259.

103. Gryta M. Fouling in direct contact membrane distillation process. J. Membr. Sci. 2008;325:383-394.

104. Khayet M, Mengual JI, Matsuura T. Porous hydrophobic/hydrophilic composite membranes: Application in desalination using direct contact membrane distillation. $J$. Membr. Sci. 2005;252:101-113.

105. Phattaranawik J, Jiraratananon R, Fane AG. Heat transport and membrane distillation coefficients in direct contact membrane distillation. J. Membr. Sci. 2003;212:177-193.

106. Qtaishat M, Matsuura T, Kruczek B, et al. Heat and mass transfer analysis in direct contact membrane distillation. Desalination 2008;219:272-292.

107. Yun Y, Ma R, Zhang W, et al. Direct contact membrane distillation mechanism for high concentration $\mathrm{NaCl}$ solutions. Desalination 2006;188:251-262.

108. Lawson KW, Lloyd DR. Membrane distillation. J. Membr. Sci. 1997;124:1-25.

109. Kalla S, Upadhyaya S, Singh K, et al. Experimental and mathematical study of air gap membrane distillation for aqueous HCl azeotropic separation. J. Chem. Technol. Biotechnol. 2019;94:63-78.

110. Thiruvenkatachari R, Manickam M, Ouk Kwon T, et al. Separation of water and nitric acid with porous hydrophobic membrane by air gap membrane distillation (AGMD). Sep. Sci. Technol. 2006;41:3187-3199.

111. Alkhudhiri A, Darwish N, Hilal N. Membrane distillation A comprehensive review. Desalination 2012;287:2-18.

112. Guillén-Burrieza E, Blanco J, Zaragoza G, et al. Experimental analysis of an air gap membrane distillation solar desalination pilot system. J. Membr. Sci. 2011;379:386-396.

113. Duong HC, Chivas AR, Nelemans B, et al. Treatment of RO brine from CSG produced water by spiral-wound air gap membrane distillation - A pilot study. Desalination 2015;366: 121-129.

114. Li Y, Tian K. Application of Vacuum Membrane Distillation in Water Treatment. J. Sust. Dev. 2009;2:183-186. 
115. Chiam CK, Sarbatly R. Vacuum membrane distillation processes for aqueous solution treatment-A review. Chem. Eng. Process - Process Intensif 2013;74:27-54.

116. Ramlow H, Machado RAF, Bierhalz ACK, et al. Dye synthetic solution treatment by direct contact membrane distillation using commercial membranes. Environ. Technol. 2020;41(17): 2253-2265.

117. Vandevivere PC, Bianchi R, Verstraete W. Treatment and reuse of wastewater from the textile wet-processing industry: Review of emerging technologies. J. Chem. Technol. Biotechnol. 1998;72:289-302.

118. Ramlow H, Correa VHM, Machado RAF, et al. Intensification of water reclamation from textile dyeing wastewater using thermal membrane technologies - Performance comparison of vacuum membrane distillation and thermopervaporation. Chem. Eng. Process - Process Intensif 2019;146:107695.

119. Leaper S, Abdel-Karim A, Gad-Allah TA, et al. Air-gap membrane distillation as a one-step process for textile wastewater treatment. Chem. Eng. J. 2019;360:1330-1340.

120. Silva R de S, Ramlow H, Cavalcanti CDÁK, et al. Steady state evaluation with different operating times in the direct contact membrane distillation process applied to water recovery from dyeing wastewater. Sep. Purif. Technol. 2020;230: 115892.

121. Laqbaqbi M, García-Payo MC, Khayet M, et al. Application of direct contact membrane distillation for textile wastewater treatment and fouling study. Sep. Purif. Technol. 2019;209: 815-825.

122. García JV, Dow N, Milne N, et al. Membrane distillation trial on textile wastewater containing surfactants using hydrophobic and hydrophilic-coated polytetrafluoroethylene (PTFE) membranes. Membranes (Basel) 2018;8:.

123. Li X, Deng L, Yu X, et al. A novel profiled core-shell nanofibrous membrane for wastewater treatment by direct contact membrane distillation. J. Mater. Chem. A 2016;4:14453-14463.

124. An AK, Guo J, Jeong S, et al. High flux and antifouling properties of negatively charged membrane for dyeing wastewater treatment by membrane distillation. Water Res. 2016;103:362-371.

125. Mokhtar NM, Lau WJ, Ismail AF. Dye wastewater treatment by direct contact membrane distillation using polyvinylidene fluoride hollow fiber membranes. J. Polym. Eng. 2015;35: 471-479.

126. Qu D, Qiang Z, Xiao S, et al. Degradation of Reactive Black 5 in a submerged photocatalytic membrane distillation reactor with microwave electrodeless lamps as light source. Sep. Purif. Technol. 2014;122:54-59.

127. Criscuoli A, Zhong J, Figoli A, et al. Treatment of dye solutions by vacuum membrane distillation. Water Res. 2008;42: 5031-5037.

128. Tomaszewska M. Membrane Distillation - Examples of Applications in Technology and Environmental Protection. Polish J. Environ. Stud. 2000;9:27-36.

129. Suk DE, Matsuura T. Membrane-based hybrid processes: A review. Sep. Sci. Technol. 2006;41:595-626.

130. Wang KY, Teoh MM, Nugroho A, et al. Integrated forward osmosis-membrane distillation (FO-MD) hybrid system for the concentration of protein solutions. Chem. Eng. Sci.
2011;66:2421-2430.

131. Ge Q, Wang P, Wan C, et al. Polyelectrolyte-promoted Forward Osmosis-Membrane Distillation (FO-MD) hybrid process for dye wastewater treatment. Environ. Sci. Technol. 2012;46: 6236-6243.

132. Parakala S, Moulik S, Sridhar S. Effective separation of methylene blue dye from aqueous solutions by integration of micellar enhanced ultrafiltration with vacuum membrane distillation. Chem. Eng. J. 2019;375:122015.

133. Hou R, Gao Y, Zhu H, et al. Coupling system of $\mathrm{Ag} / \mathrm{BiOBr}$ photocatalysis and direct contact membrane distillation for complete purification of $\mathrm{N}$-containing dye wastewater. Chem. Eng. J. 2017;317:386-393.

134. Yatmaz HC, Dizge N, Kurt MS. Combination of photocatalytic and membrane distillation hybrid processes for reactive dyes treatment. Environ. Technol. (United Kingdom) 2017;38: 2743-2751.

135. Van Der Bruggen B. Integrated membrane separation processes for recycling of valuable wastewater streams: Nanofiltration, membrane distillation, and membrane crystallizers revisited. Ind. Eng. Chem. Res. 2013;52:10335-10341.

136. Grzechulska-Damszel J, Mozia S, Morawski AW. Integration of photocatalysis with membrane processes for purification of water contaminated with organic dyes. Catal Today 2010;156:295-300.

137. Curcio E, Ji X, Di Profio G, et al. Membrane distillation operated at high seawater concentration factors: Role of the membrane on $\mathrm{CaCO}_{3}$ scaling in presence of humic acid. J. Membr. Sci. 2010;346:263-269.

138. Krivorot M, Kushmaro A, Oren Y, et al. Factors affecting biofilm formation and biofouling in membrane distillation of seawater. J. Membr. Sci. 2011;376:15-24.

139. Gryta M. Effect of iron oxides scaling on the MD process performance. Desalination 2007;216:88-102.

140. Srisurichan S, Jiraratananon R, Fane AG. Humic acid fouling in the membrane distillation process. Desalination 2005;174: 63-72.

141. Huang J, Luo J, Chen X, et al. How Do Chemical Cleaning Agents Act on Polyamide Nanofiltration Membrane and Fouling Layer? Ind. Eng. Chem. Res. 2020;59:17653-17670.

142. Fortunato L, Elcik H, Blankert B, et al. Textile dye wastewater treatment by direct contact membrane distillation: Membrane performance and detailed fouling analysis. J. Membr. Sci. 2021;636:119552.

143. Khoshnevisan S, Bazgir S, Bazgir S. Treatment of dye wastewater by direct contact membrane distillation using superhydrophobic nanofibrous high-impact polystyrene membranes. Int. J. Environ. Sci. Technol. 2021;18:1513-1528.

144. Lu X, Peng Y, Qiu H, et al. Anti-fouling membranes by manipulating surface wettability and their anti-fouling mechanism. Desalination 2017;413:127-135.

145. An AK, Guo J, Lee EJ, et al. PDMS/PVDF hybrid electrospun membrane with superhydrophobic property and drop impact dynamics for dyeing wastewater treatment using membrane distillation. J. Membr. Sci. 2017;525:57-67.

146. Mousavi SA, Arab Aboosadi Z, Mansourizadeh A, et al. Surface modified porous polyetherimide hollow fiber membrane for 
sweeping gas membrane distillation of dyeing wastewater. Colloids Surf. A: Physicochem. Eng. Asp. 2021;610:125439.

147. Tan YZ, Chew JW, Krantz WB. Effect of humic-acid fouling on membrane distillation. J. Membr. Sci. 2016;504:263-273.

148. Huo Y, Xie Z, Wang X, et al. Methyl orange removal by combined visible-light photocatalysis and membrane distillation. Dye Pigment 2013;98:106-112.

149. Goh S, Zhang J, Liu Y, et al. Fouling and wetting in membrane distillation (MD) and MD-bioreactor (MDBR) for wastewater reclamation. Desalination 2013;323:39-47.

150. Cerneaux S, Struzyńska I, Kujawski WM, et al. Comparison of various membrane distillation methods for desalination using hydrophobic ceramic membranes. J. Membr. Sci. 2009;337:55-60.

151. García-Payo MC, Essalhi M, Khayet M. Effects of PVDF-HFP concentration on membrane distillation performance and structural morphology of hollow fiber membranes. J. Membr. Sci. 2010;347:209-219.

152. Gryta M. Influence of polypropylene membrane surface porosity on the performance of membrane distillation process. $J$. Membr. Sci. 2007;287:67-78.

153. Larbot A, Gazagnes L, Krajewski S, Bukowska M, Kujawski K. Water desalination using ceramic membrane distillation. Desalination 2004;168:367-372.

154. Prince JA, Singh G, Rana D, et al. Preparation and characterization of highly hydrophobic poly(vinylidene fluoride) - Clay nanocomposite nanofiber membranes (PVDF-clay NNMs) for desalination using direct contact membrane distillation. $J$. Membr. Sci. 2012;397-398:80-86.

155. Wang P, Chung TS. A new-generation asymmetric multi-bore hollow fiber membrane for sustainable water production via vacuum membrane distillation. Environ. Sci. Technol. 2013;47:6272-6278.

156. Ishino T, Nabata N, Maeoka T. Porous polytetrafluoroethylene membrane, process for producing the same, sheet-form polytetrafluoroethylene molding, and air filter medium. Google Patents 1997.

157. Kitamura T, Kurumada KI, Tanigaki M, et al. Formation mechanism of porous structure in polytetrafluoroethylene (PTFE) porous membrane through mechanical operations. Polym. Eng. Sci. 1999;39:2256-2263.

158. Chandavasu C, Xanthos M, Sirkar KK, et al. Polypropylene blends with potential as materials for microporous membranes formed by melt processing. Polymer (Guildf) 2001;43:781-795.

159. Tabatabaei SH, Carreau PJ, Ajji A. Microporous membranes obtained from polypropylene blend films by stretching. $J$. Membr. Sci. 2008;325:772-782.
160. Sukitpaneenit $P$, Chung TS. Molecular elucidation of morphology and mechanical properties of PVDF hollow fiber membranes from aspects of phase inversion, crystallization and rheology. J. Membr. Sci. 2009;340:192-205.

161. Camacho LM, Dumée L, Zhang J, et al. Advances in membrane distillation for water desalination and purification applications. Water (Switzerland) 2013;5:94-196.

162. Hendren ZD, Brant J, Wiesner MR. Surface modification of nanostructured ceramic membranes for direct contact membrane distillation. J. Membr. Sci. 2009;331:1-10.

163. Wang Z, Hou D, Lin S. Composite Membrane with Underwater-Oleophobic Surface for Anti- Oil-Fouling Membrane Distillation. Environ. Sci. Technol. 2016:50(7): 3866-3874.

164. Liao Y, Loh C, Wang R, et al. Electrospun Superhydrophobic Membranes with Unique Structures for Membrane Distillation. ACS Appl. Mater. Interfaces 2014;6(18):1603516048.

165. Dong B Bin, Wang FH, Yang MY, et al. Polymer-derived porous SiOC ceramic membranes for efficient oil-water separation and membrane distillation. J. Membr. Sci. 2019;579:111-119.

166. Deng L, Li P, Liu K, et al. Robust superhydrophobic dual layer nanofibrous composite membranes with a hierarchically structured amorphous polypropylene skin for membrane distillation. J. Mater. Chem. A 2019;7:11282-11297.

167. Jafari A, Kebria MRS, Rahimpour A, et al. Graphene quantum dots modified polyvinylidenefluride (PVDF) nanofibrous membranes with enhanced performance for air Gap membrane distillation. Chem. Eng. Process - Process Intensif. 2018;126: 222-231.

168. Zahirifar J, Moosavian SMA, Hadi A, et al. Fabrication of a novel octadecylamine functionalized graphene oxide/PVDF dual-layer flat sheet membrane for desalination via air gap membrane distillation. Desalination 2018;428:227-239.

169. Korolkov IV, Gorin YG, Yeszhanov AB, et al. Preparation of PET track-etched membranes for membrane distillation by photo-induced graft polymerization. Mater. Chem. Phys. 2018;205:55-63.

170. Boo C, Lee J, Elimelech M. Omniphobic Polyvinylidene Fluoride (PVDF) Membrane for Desalination of Shale Gas Produced Water by Membrane Distillation. Environ. Sci. Technol. 2016;50:12275-12282.

171. Zhang J, Song Z, Li B, et al. Fabrication and characterization of superhydrophobic poly (vinylidene fluoride) membrane for direct contact membrane distillation. Desalination 2013;324:1-9. 